\title{
A study of Epidemiological Characteristicsand Weather Elements influencing COVID-19 Positive Autopsy Cases Studied at B.H.U, Varanasi, U.P
}

\author{
Deepa Durga Roy ${ }^{1}$, ManojKumar Pathak ${ }^{2}$ \\ ${ }^{1}$ Assistant Professor, Department of Forensic Medicine \& Toxicology, Banaras Hindu University, Varanasi, \\ Uttar Pradesh, ${ }^{2}$ Professor, Department of Forensic Medicine \& Toxicology, AIIMS Patna, Bihar
}

\begin{abstract}
The ongoing Severe acute respiratory syndrome coronavirus-2 (SARS-CoV-2) pandemic has prevailed and continues to persist in the country and the world despite all preventive and regulatory measures taken by the government, health care and at an individual level. It does beg the question, why?

It can be safely attributed to the fact that we are still learning about the epidemiological factors, the virological characteristics, clinical profile and the transmission dynamics of the disease. The situation is particularly challenging when we are coupling research to answer these questions while taking on board, precautionary measures to contain the tumultuous morbidities and mortality by rationing the scarce resources and manpower. The present study aims to provide an auxiliary insight into the epidemiological, topographic and weatherelements influencing COVID-19 from the 34 COVID-19 positive dead bodies sent for autopsy to Department of Forensic Medicine at Institute of Medical Sciences, Banaras Hindu University from 1 Feb 2020 to 31 March 2021. It also examines the counter productiveness for autopsy in certified cases of death with COVID-19 positive status in a common mortuary setup in India.
\end{abstract}

Key words: Autopsy;Coronavirus Disease (COVID-19);Epidemiological characteristics; Geographical distribution; Needless autopsy; Severe acute respiratory syndrome coronavirus-2 (SARS-CoV-2);Weather

\section{Introduction}

TheCoronavirus Disease (COVID-19) has terrorised the world since itsemergence in Wuhan, China in December 2019 till date. The inception of the name severe acute respiratory syndrome coronavirus 2 ("SARS-CoV-2") is attributed to the crown of glycoprotein spikes present on the enveloped single stranded RNA virus.

\section{Corresponding Author:}

\section{Dr. Deepa Durga Roy}

Assistant Professor, Department of Forensic Medicine

\& Toxicology, Banaras Hindu University, Varanasi,

Uttar Pradesh - 221005

Email id: deepadurgaroy@gmail.com
SARS-CoV-2 also known as 2019 novel coronavirus (2019-nCOV) is one of the seven virulent strains \& a highly pathogenic beta human CoVwhich causes symptoms ranging from none at all (the asymptomatic who can still spread the virus ${ }^{(1)}$ to viral pneumonia-like features commonly resulting in loss of taste, fever, malaise, cough, breathlessness, diarrhea, vomiting, coagulopathies, immune dysfunction,ARDS, multiorgan failure and even neurological symptoms ${ }^{(2)}$ (3) (4). While previously it was believed that co-existing medical conditions like asthma, cardiovascular disorders, hypertension, diabetes, extremes of age are more susceptible to COVID-19 mortality ${ }^{(5)}$, however, recent data suggests that even young adults are prone to ARDS and multiorgan failure from SARS-CoV-2 (6). The SARS-CoV-2 enters into a human host and acts on the Angiotensin I-converting enzyme 2 of the alveolar 
cells which is its binding site. ${ }^{(7)(8)(9)}$ Autopsy pulmonary findings in SARS-CoV-2 caseshave demonstrated alveoli filled with copious exudative fluid, mucus, WBC infiltrate and remnant of the necrosedpneumocytes ${ }^{(10)}$ However until present times, there is still a lacuna in understanding the pathophysiology of this virus, its epidemiological parameters and transmission characteristics thus resulting in the persistence of the pandemic and emergence of newer variants across the world. While in India, the initial rampant transmission was attributed to travel from countries which were already affected however the cases continued to rise despite government imposed lockdowns, active surveillance systems like Integrated Disease Surveillance Programme supplemented by the AarogyaSetu app , rigorous testing, quarantine and travel bans apart from individual personal protection steps like hand washing, use of alcohol based sanitizers, face masks and other personal protection equipment, sanitisation of surfaces, social distancing. This had resulted in heavy economic losses and crippling of the medical infrastructure ${ }^{(11)(12)}$ (13)(14).

Amongst the transmission factors studied, weather was of significant interest believing that warmer temperature may reduce the severity of the pandemic. However weather, in particular temperature showed no correlation to the disease. Surprisingly humidity was found to be a stakeholder in the disease transmissibility where $3-9 \mathrm{~g} / \mathrm{m} 3$ of humidity was found to be associated positively as a risk factor ${ }^{(15)}$.

In India while the transmission rate is found to be high unaffected by the tropical climate, a speedy recovery (average 11-25 days) has also been noted with low mortality. An urban, male predisposition of cases has been observed in an age group of 20-59 years ${ }^{(16)}$.

However a concerning development has been emergence of the SARS-CoV-2 Variants. A variant of the virus emerges when the predecessor virus undergoes mutation. The recent significant COVID-19 variants have been the B.1.1.7, the B.1.351 and the P.1 in the UK, South Africa and Brazil respectively detected inJanuary 2021. A particular mutation amongst the many, named D614G is common amongst all the aforementioned variant. It allows them to be more infectious making even the younger age group susceptible. ${ }^{(17)}$

India began its vaccination drive against the SARSCoV-2 with two vaccines Covaxin and Covishield on January 16,2021 . The national immunisation programme against COVID-19 which began withfocussing on the healthcare workers, public frontline workers, age group over 50 years, susceptible population with comorbid conditions have as of 18 February,2021 shown the highest cumulative numbers of vaccinated people ${ }^{(18,19)}$. Covaxin is a inactivated vaccine, developed by Indian company Bharat Biotech, which has two doses to be given with an interval of 4 weeks while Oxford-AstraZeneca's 'Covishield, is prepared from chimpanzees adenovirus modified to mimic coronavirus, and also has two doses to be administered a month to 3 months apart. PfizerBioNTech vaccine which is being used in other countries poses a storage problem in India where storing the vaccine at $-70 \mathrm{C}$ is difficult owing to the tropical climate (20)

It is believed that while Covaxinand Covishield vaccines may be effective against the UK variant, however there is no data in favour of their efficacy against South African and Brazilian variants of SARS-CoV-2 . Consequently, the Indian population remains vulnerable to COVID-19 virus ${ }^{(21)}$

The ICMR had provided a draft in 2020 recommending standard operating guidelines for performing medicolegal autopsy. The SOP was aimed at providing practical directions keeping in mind the mortuary framework and manpower. It focused on the fact that as most COVID-19 cases are known cases and would be categorised as natural deaths, hence needless autopsies should be avoided. In the event that the investigating officer cannot waive off the autopsy, post mortem examination should be carried out avoiding unnecessary invasive procedures and contact with body secretions. Methods and precautions while performing 
Medico-legal Update, October-December 2021, Vol.21, No. 419

the autopsy, cleaning and disinfecting the mortuary premises, handling and handing over of a COVID-19 positive body, ethical and legal aspects have been comprehensively detailed in the draft. ${ }^{(22)}$

\section{Objectives:}

1. To study the causes of death in COVID-19 positive cases which warranted an autopsy

2. To determine the sex distribution in the COVID-19 positive cases sent for autopsy

3. To determine the age group in whichCOVID-19 positive deaths were more prevalent.

4. To study which months of the year had the highest case load.

5. To study the geographical distribution of these cases.

6. To study the difference in the case load post commencement of vaccination drives(which was initiated on 16 Jan 2021 pan India).

\section{Material and Methods}

The data on the number of COVID 19 deaths sent for autopsy, were collected from the mortuary register in the Department of Forensic Medicine at Institute of Medical Sciences, Banaras Hindu University from 1 Feb 2020 (first case in India reported on 30 Jan 2020) to 31 March 2021. The case information (numbered as per autopsy chronology) such as their gender, age, residence, causeand month of death was analysed as a part of retrospective observational study.RT-PCRtest reports done during the course of hospital admission which were attached to the autopsy requisition were assessed. The datasets used have been made available by theDepartment of Forensic Medicine at Institute of Medical Sciences, Banaras Hindu University and does not include any patient identifying information.

\section{RESULT\& DISCUSSION:}

Causes of death in COVID-19 positive cases which warranted an autopsy

Amongst a total of 34 COVID 19 positive autopsy cases studied, deaths recorded were highest in number (13cases) due to road traffic accidents (RTA), followed by unknown cause of death at the time of certification of death in hospital (12 cases). The other causes being head injury, burn injury, liver injury, drowning, myocardial infarction (MI), chronic kidney disease (CKD), type 2 Diabetes Mellitus in descending order.

It is important to discuss here that none of the cases fit in the category which warranted an absolute need for performing an invasive autopsy as most were certified causes of hospital deaths. This, coupled with the fact that COVID-19 is a highly infective viruswhich puts the mortuary manpower at unnecessary risk. The limited availability of PPE kits, overload of cases, limited resources and hands makes cleaning and sanitisation of mortuary after every case difficult further posing as a significant bio hazard. Despite the ICMR 2020 guidelines and Sec $174 \mathrm{CrPC}$ which allows the investigating officer to forego a needless autopsy there is muchbureaucratic reluctance and hesitation on the part of the treating doctor to issue the certificate of cause of death ${ }^{(22)}$. This is in concurrence with observations made by Parekh, U., $\&$ Kanchan, $\mathrm{T}$ where they have discussed the pitfalls of conducting rampant autopsies in the era of COVID-19 pandemic ${ }^{(23)}$ (Fig. 1) 


\section{Cause of death}

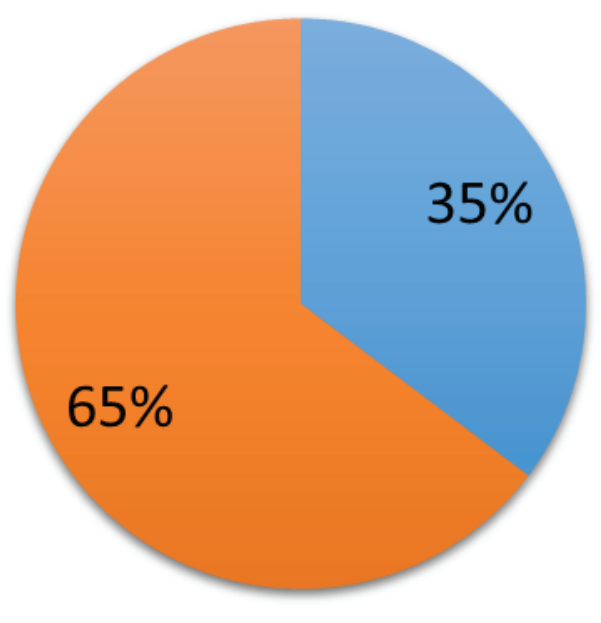

Unknown cause of death

Other causes of death in COVID positive cases

Fig.1 : The pie chart depicts that a bulk of the COVID-19 positive cases already had a known cause of death

Gender distribution in the COVID-19 positive cases sent for autopsy.

There was male predominance in the autopsy cases studied, with a significant 85 percent of the case load being men. This is in concurrence with study by Peckham, H., de Gruijter, N.M., Raine, C. et al. who cited a male bias of COVID-19 mortality. They attributed the same to an inferior immune response of males. They noted a higher levels of CD4+ Tcells, CD8 $+\mathrm{T}$ cell,B- cells and type 1 interferon (IFN) in females. The interferon is anti-viral in nature which is proportional to the number of $\mathrm{X}$ chromosomes thus providing added protection against COVID-19. Oestradiol has also been considered advantageous as it augments production of immune cells thus proving as an asset against the SARS-COV 2.

Socio-cultural differences have also been implicated as a culprit in the gender prejudice for COVID-19 mortality. Men are more likely to go out and socialise in crowded places, not wash hands as frequently, follow unhealthy practices like smoking and alcoholism which predispose them to have an increased propensity to comorbidities that influence the fatality rate in COVID-19. (24)

Age group in which COVID-19 positive deaths were more prevalent.

The maximum number of cases with a positive COVID-19 report were noted in the age groups 21-30 years ( 7 cases) and 11-20 years ( 6 cases) while the lowest were reported in the age beyond 71 years ( a total of 3 cases). However in ten out of the thirteen COVID-19 positive cases in the age group of 11-30 years, cause of death was other than sequelae of SARS-COV2 (road traffic accident, burn injury \& drowning) thus pointing to the fact that the age distribution data obtained from this study may be skewed. (Fig.2) 


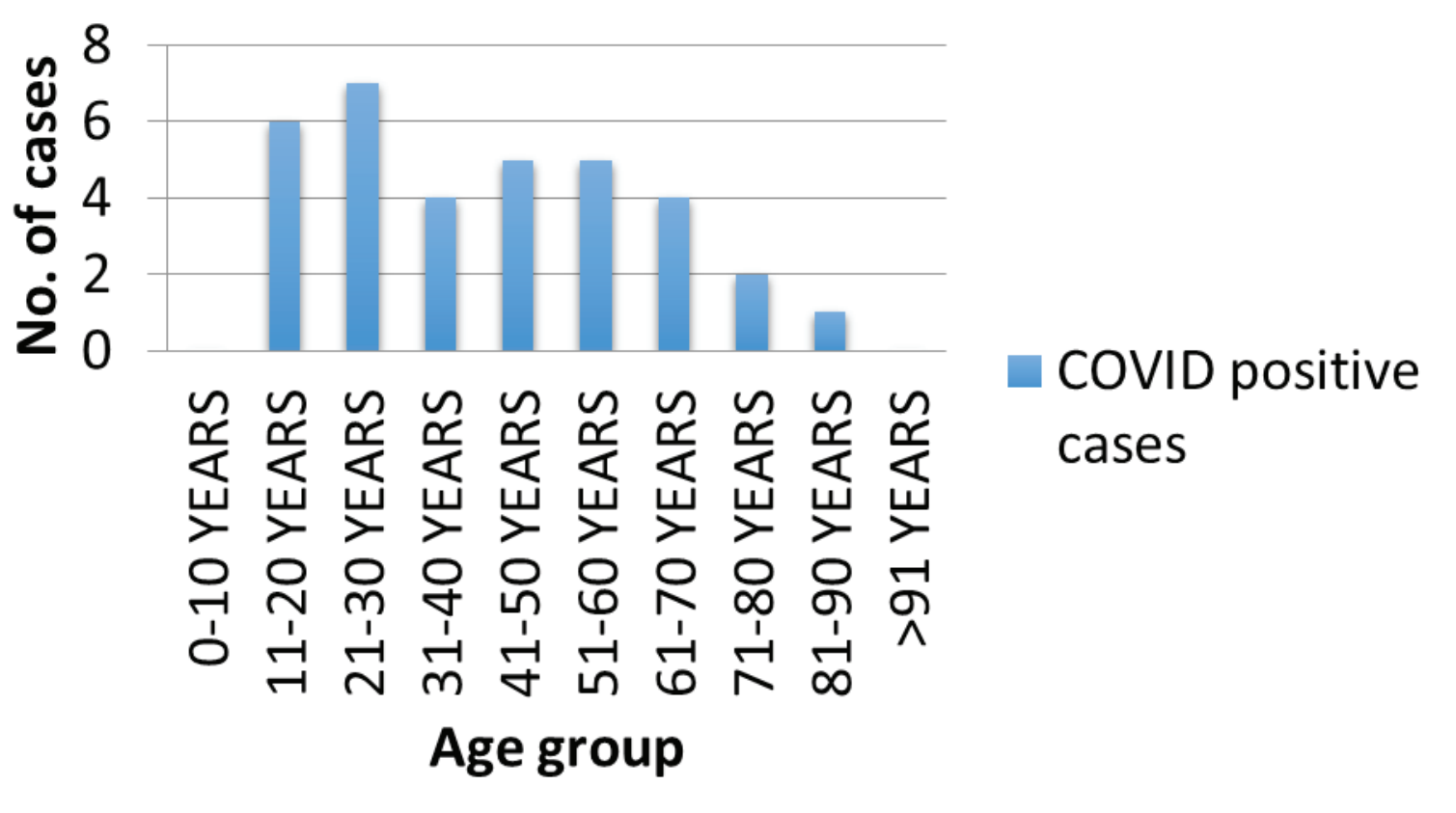

Fig.2: The bar graph represents the number of COVID-19 positive autopsy cases in the various age groups.

A study byAsirvatham E.S, Jones C et al, validates the popular theory of advanced age being more susceptible to succumbing to COVID-19 due to pervasiveness of comorbidities and decreased ability to mount an adequate immune response. ${ }^{(25)}$

Months of the yearwhich had the highest case load.

The number of cases(23 cases)peaked in the months of August- October when the absolute humidity range also increases in Uttar Pradesh, Bihar and M.P.(Fig.3)

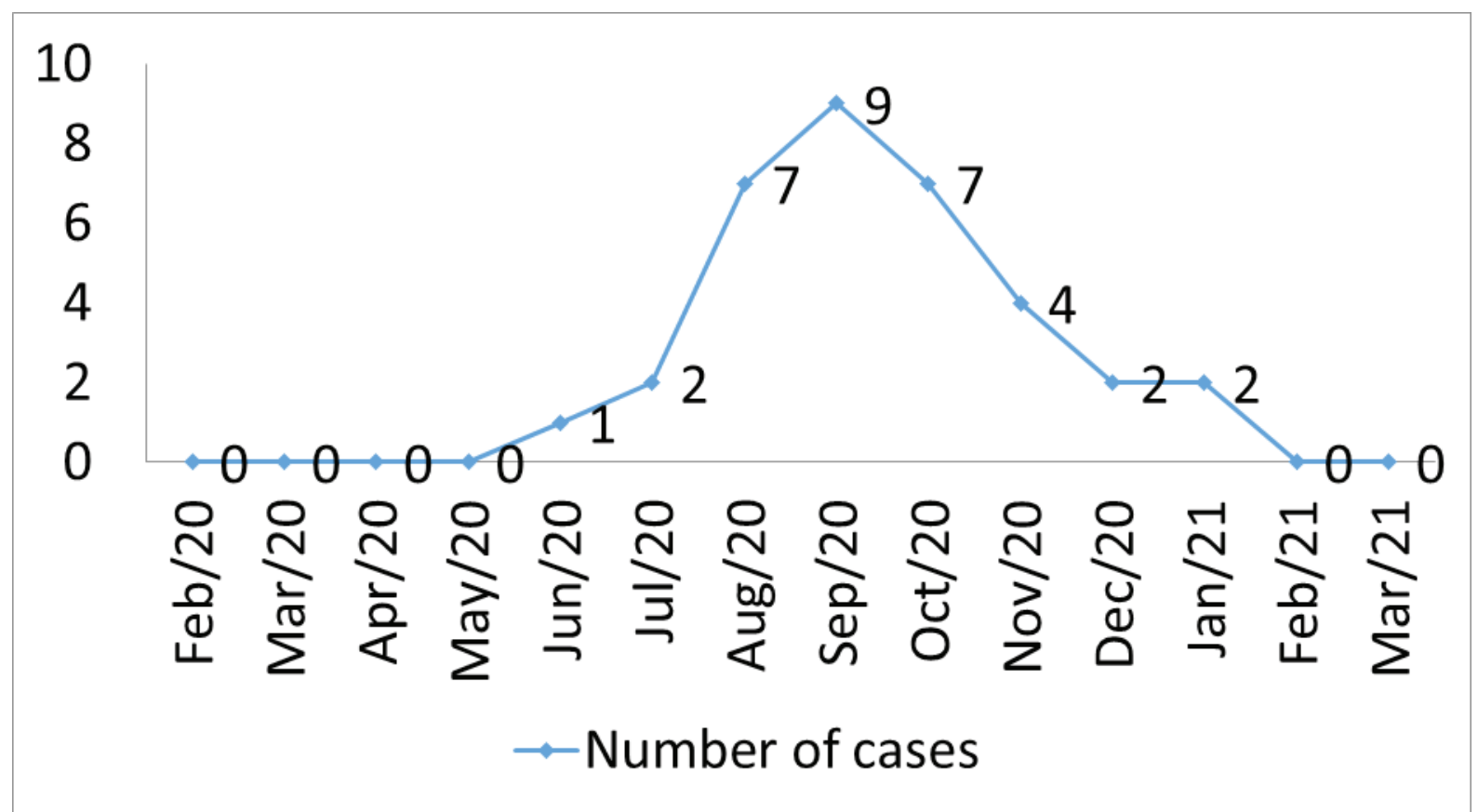

Fig.3: Month-wise distribution of case load from February 1,2020 to March 31,2021 
The finding is in agreement with study conducted by Chanda $\mathrm{A}$ where he modelled a study to observe the relationship between COVID-19 cases and various meteorological parameters like temperature and humidity. He noted that while temperature did not hold any bearing on the infectivity rate of COVID-19, a higher humidity range was positively associated with disease transmission and case load. ${ }^{(26)}$

\section{Geographical distribution}

The maximum number of cases were from the state of Uttar Pradesh. This was followed by states which shared their borders with Uttar Pradesh like Bihar and Madhya Pradesh.

There was no parallelism noted between state population density and the autopsy cases with positive RT-PCR report for COVID-19 which is in concurrence with Chanda A. In his study he furthermore did not infer any state wise rural or urban susceptibility to the virus. (26)

Difference in the case load post commencement of vaccination drives in India which began on 16 Jan 2021.

There was a significant reduction in the COVID-19 positive autopsy cases being sent to mortuary since January 2021 till March 31 ${ }^{\text {st }}$, 2021 with only 2 cases in the month of January and none there on. However whether this can be attributed to a natural decline of cases from herd immunity or the vaccination drive or laxity in testing of admitted cases, it cannot be conclusively ascertained and needs more extensive study.

\section{Conclusion}

The study attempts to examine the various elements like age, gender, regional distribution, weather that can have a bearing on the COVID-19 positive cases being sent for autopsy in BHU, Varanasi. The results lead us to have a better understanding as to why these cases are being sent for autopsy and forces us to scrutinise if a post mortem examination is truly essential in a certified COVID-19 case with known cause of death.
The COVID-19 pandemic is here to stay and may possibly evolve for the worse. A relentless and unceasing search for causative factors is the only path forwards.

Financial Support: No funding was received for this study

Conflict of Interest. : None

Ethical Clearance: It was obtained from Institutional Ethical Committee

\section{References}

1. Norgady , B. What the data say about asymptomatic COVID infections [Internet] Naturecom. [Online]. Available from: https:// www.nature.com/articles/d41586-020-031413 [Accessed cited 25 March 2021]

2. Shereen M, Khan S, Kazmi A, Bashir N, Siddique R. COVID-19 infection: Emergence, transmission, and characteristics of human coronaviruses. Journal of Advanced Research. 2020;24:91-98.

3. Chen N, Zhou M, Dong X, Qu J, Gong F, Han Y et al. Epidemiological and clinical characteristics of 99 cases of 2019 novel coronavirus pneumonia in Wuhan, China: a descriptive study. The Lancet. 2020;395(10223):507-513.

4. Marshall, Paterson et al.,Huang C, Wang Y, Li $\mathrm{X}$, Ren L, Zhao J, Hu Y et al. Clinical features of patients infected with 2019 novel coronavirus in Wuhan, China. The Lancet. 2020;395(10223):497506

5. Bialek S, Boundy E, Bowen V, Chow N, Cohn A, Dowling $\mathrm{N}$ et al. Severe Outcomes Among Patients with Coronavirus Disease 2019 (COVID-19) - United States, February 12-March 16, 2020. MMWR Morbidity and Mortality Weekly Report. 2020;69(12):343-346

6. Song W, Gui M, Wang X, Xiang Y. CryoEM structure of the SARS coronavirus spike glycoprotein in complex with its host cell receptor ACE2. PLOS Pathogens. 2018;14(8).

7. Li F, Guo YR, Cao QD, Hong ZS, Tan YY, Chen $\mathrm{SD}$, Jin HJ, et al. Structure of SARS Coronavirus Spike Receptor-Binding Domain Complexed with Receptor. Science. 2005;309(5742):1864-1868.

8. Guo Y, Cao Q, Hong Z, Tan Y, Chen S, Jin H et al. The origin, transmission and clinical therapies on 
coronavirus disease 2019 (COVID-19) outbreak an update on the status.Military Medical Research. 2020;7(1).

9. Carsana L, Sonzogni A, Nasr A, Rossi R, Pellegrinelli A, Zerbi $\mathrm{P}$ et al. Pulmonary postmortem findings in a series of COVID-19 cases from northern Italy: a two-centre descriptive study. The Lancet Infectious Diseases. 2020;20(10):11351140

10. Maiese A, Manetti AC, La Russa R, et al. Autopsy findings in COVID-19-related deaths: a literature review .Forensic SciMed Pathol. 2020;1-18.

11. India under COVID-19 lockdown [Online]. Available from: The Lancet 395(10223), 1315. doi: 10.1016/S0140-6736(20)309387 [Accessed cited 25 March 2021]..

12. Pulla, P. Covid-19: India imposes lockdown for 21 days and cases rise [Online]. Available from: doi: 10.1136/bmj.m1251. [Accessed cited 25 March 2021].

13. Dehal N, Krishan K, Kanchan T, Unnikrishnan B, Singh J. Integrated disease surveillance in India progress and pitfalls. Perspectives in Public Health. 2015;135(6):290-290

14. Garg S, Bhatnagar N and Gangadharan N (2020) A case for participatory disease surveillance of the COVID-19 pandemic in India. JMIR Public Health and Surveillance 6(2), e18795 (1-5).

15. Pan J, Yao Y, Liu Z, Meng X, Ji JS, Qiu Y, Wang W, Zhang L, Wang W, Kan H. Warmer weather unlikely to reduce the COVID-19 transmission: An ecological study in 202 locations in 8 countries. Sci Total Environ. 2021 Jan 20;753:142272.

16. Gupta S, Raghuwanshi GS and Chanda A Effect of weather on COVID-19 spread in the US: a prediction model for India in 2020. Science of Total Environment. 2020;728(13): 1-8

17. Cases, Data, and Surveillance [Internet]. Centers for Disease Control and Prevention. 2021 [cited 25 March 2021]. Available from: https://www.cdc. gov/coronavirus/2019-ncov/cases-updates/variantsurveillance/variant-info.html. [Accessed cited 28 March 2021].

18. India's vaccine production capacity is best asset world has today, says UN chief [Internet]. Hindustan Times. 2021. Available from: https:// www.hindustantimes.com/world-news/indiasvaccine-production-capacity-is-best-asset-world-
Medico-legal Update, October-December 2021, Vol.21, No. 423 has-today-says-un-chief-101611886527685. html. [Accessed cited 28 March 2021].

19. Coronavirus in India: Latest Map and Case Count [Internet]. Covid19india.org. 2021 Available from: https://www.covid19india.org/[Accessed cited 28 March 2021].

20. User S. Vaccine information, ICMR New delhi COVID-19 Vaccine [Internet]. Vaccine.icmr.org. in. 2021. Available from: https://vaccine.icmr. org.in/covid-19-vaccine[Accessed cited 29 March 2021]

21. News I. No data on efficacy of India's Covid vaccines against South African, Brazilian variants: Scientists | India News - Times of India [Internet]. The Times of India. 2021.Available from:http://timesofindia. indiatimes.com/articleshow/81069891. cms?utm_source $=$ contentofinterest $\&$ utm medium $=$ text\&utm_campaign $=$ cpps[Accessed cited 29 March 2021]

22. Standard guidelines for medico-legal autopsy in COVID-19 deaths in India. https://eaaf.org/wpcontent/uploads/covid19 PDFs/India/COVID19 AUTOPSY_GUIDELINES_2020_10052020.pdf [accessed 25 March 2021]

23. Parekh, U., \& Kanchan, T. (2020). COVID-19 instigates resurgence of 'needless autopsies' issue in India. Journal of forensic and legal medicine, 74, 102028. https://doi.org/10.1016/j. jflm.2020.102028 [Accessed cited 29 March 2021]

24. Peckham, H., de Gruijter, N.M., Raine, C. et al. Male sex identified by global COVID-19 meta-analysis as a risk factor for death and ITU admission. Nat Commun 11, 6317 (2020). Available from :https:// doi.org/10.1038/s41467-020-19741-6. [Accessed cited 29 March 2021]

25. Asirvatham ES, Sarman CJ, Saravanamurthy SP, Mahalingam P, Maduraipandian S, Lakshmanan J. Who is dying from COVID-19 and when? An Analysis of fatalities in Tamil Nadu, India [Internet]. Clinical Epidemiology and Global Health. Elsevier; 2020Available from: https://www.sciencedirect. com/science/article/pii/S2213398420302189 [Accessed cited 29 March 2021]

26. Chanda A. COVID-19 in India: transmission dynamics, epidemiological characteristics, testing, recovery and effect of weather .Epidemiol Infect. 2020;148:e182. 